\title{
Reestruturação do Sistema Financeiro Internacional e Países Periféricos
}

\author{
Restructuring of the International Financial \\ System and Peripheral Countries
}

MARIA CRISTINA PENIDO DE FREITAS*,** DANIELA MAGALHÃES PRATES ${ }^{+,++}$

RESUMO: O objetivo deste artigo é apresentar uma avaliação das proposições de reformulação do sistema financeiro internacional e suas prováveis consequências para a soberania nacional dos países subdesenvolvidos. Para atingir esse objetivo, o artigo analisa a lógica subjacente às principais recomendações políticas do FMI para a "nova arquitetura financeira internacional", as novas regras de adequação de capital elaboradas pelo Comitê da Basiléia e as propostas de reforma para o FMI e o Banco Mundial propostas pelo Congresso dos EUA e pelo governo dos EUA.

PALAVRAS-CHAVE: Sistema financeiro internacional; organizações internacionais; FMI; Banco Mundial; países periféricos.

ABSTRACT: The purpose of this article is to present an evaluation of the international financial system reformulation propositions and their likely consequences for the national sovereignty of underdeveloped countries. To attain this objective, the article analyses the underlying rationale of the IMF's main policy recommendations for the "new international financial architecture", the new capital adequacy rules drawn by the Basle Committee, and the reform proposals for the IMF and the World Bank proposed by the US Congress and by the US government.

KEYWORDS: International financial system; international organizations, IMF, World Bank, peripheral countries

JEL Classification: F33; F53; G15; O19.

* Doutora em Economia pela Universidade de Paris XIII. Email:crispenido@uol.com.br; Orcid: 00000003-4209-4570.

* * Pesquisadora sênior da Diretoria de Economia do Setor Público da Fundação do Desenvolvimento Administrativo de São Paulo - DIESP/Fundap..

+ Doutoranda do Instituto de Economia da Universidade Estadual de Campinas - IE/Unicamp, Campinas/SP, Brasil. E-mail: prates@unicamp.br; Orcid: 0000-0003-3383-5736.

++ Pesquisadora da Diretoria de Economia do Setor Público da Fundação do Desenvolvimento Administrativo de São Paulo - DIESP/Fundap. 
O debate em torno da reestruturação do sistema financeiro internacional (SFI) remonta aos anos 70, quando o colapso de Bretton Woods e a instabilidade gerada pelo novo ambiente de taxas de câmbio flutuantes e progressiva liberdade dos movimentos de capitais estimularam a formulação de várias propostas de reforma deste sistema por economistas de diferentes matrizes teóricas (Baer, 1995). Todavia, a crise asiática de meados de 1997 representou um ponto de inflexão nesse debate. Esta crise explicitou os riscos de contaminação global de desequilíbrios e/ou crises no contexto atual de globalização financeira e foi, provavelmente, a mais grave desde o colapso do sistema de Bretton Woods, em termos da sua dimensão e dos seus desdobramentos. Pela primeira vez, uma crise financeira nos "mercados emergentes" contaminou de forma imediata diversos segmentos dos mercados financeiros dos países centrais (Akyüz, 1998).

Nesse contexto, mesmo os economistas do mainstream passaram a defender propostas mais ousadas de reforma, antes restritas aos meios acadêmicos heterodoxos - como controles sobre os fluxos de capitais - e próprios organismos multilaterais passaram a admitir a necessidade de aperfeiçoar a "arquitetura financeira internacional”, cujas fragilidades tornaram-se mais do que evidentes após esta crise (Cunha e Prates, 1999). Tanto no World Economic Outlook (WEO), relatório semestral do FMI publicado em setembro de 1999 (IMF, 1999b), quanto no relatório anual do Banco Mundial de 1999 (World Bank, 1999), um capítulo é dedicado a propostas de prevenção e resolução das crises financeiras recentes.

Nesses relatórios, ambas instituições reconheceram, pela primeira vez, que as crises financeiras dos países em desenvolvimento não estiveram vinculadas somente a desajustes internos (macroeconômicos e/ou institucionais), mas também ao funcionamento inadequado e ineficiente do mercado financeiro internacional. Este mau funcionamento teria sido provocado, em grande parte, pela insuficiência e/ ou falta de transparência das informações sobre a situação macroeconômica (contas externas, fiscais etc.) e por problemas institucionais dos sistemas financeiros domésticos. Essa assimetria de informações teria induzido a tomada de decisões incorretas por parte dos bancos e investidores internacionais, num contexto de deficiências na infra-estrutura institucional, as quais constituíram obstáculos ao ajuste do sistema após a revisão dessas decisões. Contudo, a falta de transparência e a falhas institucionais teriam sido as principais, mas não as únicas responsáveis pelas crises. Dois problemas adicionais são enfatizados. Por um lado, reconhece-se que os bancos internacionais e os investidores institucionais foram negligentes na concessão de recursos para os mercados emergentes e no monitoramento dos riscos potenciais envolvidos. Por outro lado, afirma-se que parte dessa negligência foi decorrência da expectativa de que o FMI e os governos do países centrais socorreriam os países em caso de crises de liquidez ou solvência, ou seja, do problema de moral hazard, que teria se reforçado após os pacotes de salvamento (bail-outs) do FMI e do G-7 na crise do México, Ásia e Rússia (IMF, 1999c e Smalhout, 1998a).

Assim, o fortalecimento do sistema financeiro internacional deveria envolver um conjunto de iniciativas, voltadas para a resolução dessas três principais deficiências. Enquanto o FMI tem liderado os esforços voltados para a correção das "falhas de 
mercado", o Comitê da Basiléia já propôs novas regras de adequação do capital, que procuram exatamente impedir a constituição de posições arriscadas por parte dos bancos internacionais. Já o problema do moral hazard seria resolvido a partir da reforma do FMI e do BIRD, cujas linhas gerais devem seguir a proposta do governo da potência hegemônica, os EUA, divulgada no final de 1999 e reafirmada através das declarações do secretário do Tesouro no primeiro semestre de 2000.

Apesar de ser um processo em gestação e, assim, com desdobramentos ainda incertos, é possível realizar uma avaliação, ainda que preliminar, das prováveis conseqüências desse conjunto de iniciativas sobre os países periféricos. Para atingir esse objetivo, o artigo foi estruturado da seguinte forma: na seção I, apresentam-se as principais recomendações de política e iniciativas do FMI voltadas para o fortalecimento do SFI; na seção II, resumem-se as novas regras de adequação de capital propostas pelo Comitê da Basiléia; na seção III, analisam-se as propostas de reforma do FMI e do BIRD do Congresso e do governo americano; na seção IV, como considerações finais, procura-se mostrar a lógica subjacente a esse conjunto de iniciativas e discutem-se seus possíveis efeitos sobre os países periféricos.

\section{AS RECOMENDAÇÕES DE POLÍTICA E AS INICIATIVAS DO FMI}

No relatório do FMI (IMF, 1999c), o capítulo 5, denominado "Strenghtening the architecture of the international financial system", resume as propostas do Executive Board do Fundo, discutidas ao longo de 1998/99 e apoiadas pela comunidade internacional. Algumas dessas propostas já haviam sido apresentadas no WEO de maio de 1998, mas somente no WEO de 1999 o FMI reconhece, explicitamente, a necessidade de reformar o Sistema Financeiro Internacional (SFI) e apresenta de forma detalhada seis recomendações interdependentes de política.

A primeira iniciativa diz respeito à promoção da transparência e da accountability, mediante o desenvolvimento e disseminação de padrões internacionais ou códigos de good practice. O Fundo tem estimulado o desenvolvimento e a adoção de padrões internacionais nas áreas de sua direta responsabilidade (disseminação de dados, transparência das políticas monetária, fiscal e financeira), mediante o aperfeiçoamento do Special Data Dissemination Standard (SDDS) ${ }^{1}$ e, em conjunto com outras instituições, nas demais áreas: com o BIS (Bank for International Settlement), na área de supervisão bancária; com a OCDE (Organização para Cooperação de Desenvolvimento Econômico), nas áreas fiscal e de governança corporativa; e, com a International Accounting Standards Committee (IASC), no que diz respeito aos procedimentos de auditoria e contabilidade (Adams et al., 1998).

A segunda proposta refere-se ao fortalecimento dos sistemas financeiros e das práticas de supervisão do mercado, parte integrante da segunda onda de reformas

\footnotetext{
${ }^{1}$ O Special Data Dissemination Standard (SDDS), instituído em 1996, constituiu um padrão de good practice para a disseminação dos dados econômicos e financeiros dos países membros do Fundo.
} 
estruturais, que passou a ser recomendado como aspecto fundamental de prevenção das crises após a crise do México e, principalmente, dos países do sudeste asiático. O FMI, conjuntamente com o Banco Mundial, o Comitê da Basiléia para Supervisão Bancária e membros dos órgãos de supervisão de diversos países, tem atuado no sentido de desenvolver e disseminar princípios internacionais de boa conduta para o estabelecimento de sistemas financeiros sólidos. Várias iniciativas foram tomadas ao longo de 1998 com esse objetivo, dentre as quais: revisão por parte das autoridades nacionais de supervisão e regulamentação das práticas adotadas; revisão pelo Comitê da Basiléia de alguns aspectos dos princípios básicos de regulamentação bancária; criação do Financial Stability Forum, para fortalecer a cooperação entre as organizações multilaterais; estabelecimento do Financial Sector Liaison Committee (FSLC) em 1998, para aprimorar a colaboração entre o FMI e o Banco Mundial nessa área; entre outros. ${ }^{2}$

A terceira proposta refere-se à necessidade de "prestar mais atenção" na ordem da liberalização da conta de capital. Os controles temporários sobre os ingressos de capitais são considerados válidos, enquanto o ajuste macroeconômico e/ou o fortalecimento do ambiente institucional não forem atingidos. O Fundo também reconhece que há evidências de que esses controles tendem a melhorar o perfil dos ingressos. Já os controles sobre as saídas de capitais são objeto de maior controvérsia. A maioria dos diretores concordou que esses controles não constituem um instrumento efetivo numa crise; pelo contrário, podem contribuir para aumentar a severidade do ajustamento e afetar o acesso futuro dos países a fontes voluntárias de crédito. No entanto, alguns diretores ponderaram que "em uma crise, a reimposição de controles sobre as saídas de capitais - junto com um envolvimento apropriado do setor privado e no contexto de um amplo esforço de ajuste — poderia desempenhar um papel útil” (IMF; 1999c).

A quarta proposta, talvez a mais inovadora, refere-se ao maior envolvimento do setor privado na prevenção e resolução das crises, o qual seria fundamental para garantir um processo de ajustamento mais ordenado, limitar o "risco moral", fortalecer a disciplina de mercado e auxiliar os devedores dos mercados emergentes a se protegerem da volatilidade e do contágio. Dois tipos de medidas são sugeridas: (a) medidas ex ante - linhas contingentes de crédito privado, alongamento dos prazos das linhas de crédito interbancárias a partir da introdução de call options nos contratos, emissão de "structured notes", nas quais o serviço da dívida variaria contra-ciclicamente; e garantias oficiais, (b) e, ex post, como a rolagem negociada da dívida externa, que ocorreu no caso da Coréia.

A quinta proposta enfatiza a necessidade de adotar regimes cambiais adequa-

\footnotetext{
${ }^{2}$ No início de 2000, o BIS e o Comitê da Basiléia criaram o Financial Stability Institut (FSI), cujo objetivo principal é auxiliar os supervisores na implementação das diretrizes de fortalecimento dos sistemas financeiros domésticos. Dentre outras atividades, esse instituto pretende organizar seminários especiais em conjunto com o FMI e BIRD, nos quais aspectos técnicos e conceituais da supervisão financeira, dos mercados, bem como questões políticas, serão examinados por especialistas altamente qualificados.
} 
dos. O Fundo adverte que o regime de câmbio fixo estimula o endividamento externo e a subestimação do risco cambial (como observado na Ásia). Porém, também aponta que a adoção do regime de câmbio flutuante não evita, por si só, a assunção excessiva de riscos.

Finalmente, a última proposta diz respeito à ação do FMI na prevenção e resolução das crises. Nesse sentido, o Fundo aprovou, em abril de 1999, uma nova linha de crédito, a Contingent Credit Lines (CCL), direcionada para países com situação macroeconômica saudável, mas que podem enfrentar futuros problemas de balanço de pagamentos em função do efeito-contágio. A concessão dos recursos dessa linha também estará sujeita a outras condicionalidades. Para obtê-la, o país deve estar implementando políticas consideradas consistentes; seu desempenho econômico precisa ser considerado positivo na avaliação anual do FMI, que também apreciará os avanços na adoção dos padrões internacionais de boa conduta; o membro deve fazer parte do SDDS; o país deve ter relações construtivas com o credores privados e ter feito progressos no sentido de limitar sua vulnerabilidade externa mediante o manejo do seu endividamento externo e das reservas internacionais.

Assim, no WEO de 1999, ao lado das proposições de política tradicionais para a prevenção das crises financeiras dos países em desenvolvimento - busca de sólidos fundamentos econômicos e o fortalecimento da supervisão e regulamentação bancária -, o FMI também passou a defender iniciativas mais "heterodoxas", como o controle dos fluxos de capitais e o envolvimento do setor privado na prevenção e resolução das crises. Esses "recuos" em termos de proposição de política, têm um objetivo claro: aumentar o grau de resistência desse sistema a crises sistêmicas e, assim, evitar a reversão do ambiente de globalização financeira (Cunha e Prates, 1999). Segundo o FMI, o fortalecimento da arquitetura financeira seria necessário para "garantir que os benefícios potenciais da globalização atinjam todos os países membros do fundo" (IMF, 1999c: p. 42).

Nesse sentido, os controles diretos sobre os ingressos de capitais de curto prazo, nos moldes da chamada quarentena adotada pelo Chile até o início de maio de 2000, têm a função de garantir a longo prazo a abertura financeira das economias, e não a sua reversão: "controles sobre os influxos (de capitais) podem ser justificados em bases prudenciais, nas situações onde o ambiente doméstico institucional e regulatório é frágil, e como uma forma de lidar com as pressões externas dos mercados" (IMF, 1999c: 47). "Já a defesa de um maior envolvimento do setor privado na prevenção e resolução das crises surge devido ao receio de que as sucessivas crises financeiras e a fragilização das economias periféricas - mesmo das mais bem-sucedidas em termos de crescimento nas últimas décadas - criem uma desilusão em relação às virtudes intrínsecas ao sistema de mercado globalmente integrado. Ou, no limite, se convertam numa crise global, que abra espaço para propostas mais radicais de reformulação da arquitetura do sistema financeiro internacional, que resultem na reversão do ambiente de finanças globalizadas e liberalizadas - que, por sinal, já vêem sendo defendidas por alguns organismos multilaterais como a Unctad (United Nations Conference on Trade and Development) (1998)" (Cunha e Prates, 1999b). 


\section{AS NOVAS REGRAS DE ADEQUAÇÃO DE CAPITAL DO COMITÊ DA BASILÉIA}

Apesar das iniciativas recentes do FMI e do Banco Mundial, o BIS é o fórum, por excelência, das discussões e iniciativas na área de supervisão e regulamentação bancárias. As ações dessa instituição no sentido de aprimorar essa área iniciaramse em 1975, quando foi criado, no âmbito do BIS, o Basle Commitee on Banking Supervision ou Comitê da Basiléia. Desde então, esse Comitê tem procurado harmonizar os princípios de supervisão bancária em todos os países e estimular a sua aplicação em âmbito nacional e internacional. Dentre as suas iniciativas mais recentes, destacam-se o Acordo de 1988 para harmonização das regras de capital mínimo ${ }^{3}$ e os "Princípios fundamentais para uma supervisão bancária efetiva" ${ }^{4}$, de 1997 (Basle Committe, 1988 e 1997). ${ }^{5}$

O comportamento míope e negligente dos bancos internacionais no ciclo de endividamento que precedeu a crise financeira do sudeste asiático explicitou a inadequação das regras do Acordo de 1988, que permitiram, e inclusive estimularam, a concessão excessiva de créditos de curto prazo aos países do sudeste asiático e à Rússia, ao atribuírem uma baixa ponderação de risco aos créditos interbancários internacionais (Taylor, 1999). Um dos objetivos da nova proposta para a adequação de capital mínimo divulgada em junho de 1999 pelo Comitê de Supervisão Bancária do BIS, A new capital adequacy framework ${ }^{6}$, é exatamente aperfeiçoar o marco institucional de modo a evitar a excessiva tomada de risco por parte dos bancos internacionais.

Essa proposta possui três pilares disciplinares - requerimento de capital mínimo, a supervisão da adequação de capital e o fortalecimento da disciplina de mercado - e foi submetida à avaliação dos supervisores dos países membros e

\footnotetext{
${ }^{3}$ Esse acordo definiu que os bancos com atuação internacional deveriam manter um capital mínimo da ordem de $8 \%$ dos ativos ponderados pelo risco. Adicionalmente, definiu que no mínimo $50 \%$ do capital deveria ser composto por ações permanentes e reservas abertas, o chamado tiers 1 . O capital complementar (tiers 2) poderia incluir, entre outros, reservas fechadas, provisões gerais, instrumentos híbridos e débito subordinado.

${ }^{4}$ Esse documento institui 25 princípios que devem nortear as ações dos supervisores nacionais de modo a garantir uma supervisão efetiva dos sistemas financeiros domésticos, com ênfase nos mecanismos que assegurem a "disciplina do mercado" e a auto-regulação por parte das instituições bancárias.

${ }^{5}$ Para maiores detalhes sobre a atuação do Comitê da Basiléia e os efeitos das novas regras sobre os países periféricos, ver Freitas \& Prates (2000).

${ }^{6}$ De acordo com Shireff (1999), a divulgação do documento pelo Comitê de Supervisão Bancária do BIS foi postergada em virtude de divergência entre os representantes dos EUA e da União Européia tanto no que se refere à supervisão consolidada quanto ao conceito de tiers 1. Os europeus consideram que os bancos americanos escapam da supervisão consolidada por serem controlados por holding companies. Ao mesmo tempo, consideram que as autoridades de supervisão americanas têm enfraquecido o conceito de tiers 1, o qual deveria incluir exclusivamente capital e reservas, ao admitir ações de companhias de propósito especial, criadas pelos bancos. Estas deveriam ser classificadas como tiers 2. Razões concorrenciais estão levando os bancos europeus a seguirem o exemplo americano.
} 
também das instituições representativas dos bancos, como por exemplo, o IIF Institute of International Finance ${ }^{7}$, estando sob consulta até março de 2000 (Basle Committee, 1999).

O primeiro pilar trata do requerimento de capital mínimo e oferece uma matriz de classificação de crédito externo contra os quais certos níveis de capital precisam ser mantidos (ver Tabela 1). No que se refere ao risco soberano, a avaliação das agências de rating é considerado melhor que o critério anterior, de o país ser membro ou não da OCDE. O primeiro pilar também considera outros riscos enfrentados pelos bancos. Para manter um nível de capital adequado, os supervisores querem identificar e "onerar" mais os outros tipos de risco, como risco operacional e risco de taxa de juros excessivos, o que ocorre quando os bancos utilizam como funding de operações de médio prazo recursos de curto prazo sem efetuar hedge adequado.

Tabela 1: Ponderação de Risco na Nova Proposta para o Acordo de Basiléia em \%

\begin{tabular}{lcccccc}
\hline $\begin{array}{c}\text { Classificação } \\
\text { de risco }\end{array}$ & AAA a AA- & A+ a A- & BBB+ a BBB- & BB+ a B- & Abaixo de B- & sem rating \\
\hline Risco Soberano & 0 & 20 & 50 & 100 & 150 & 100 \\
Bancos (opção 1)(1) & 20 & 50 & 100 & 100 & 150 & 100 \\
Bancos (opção 2)(2) & 20 & $50(3)$ & $50^{(3)}$ & $100(3)$ & 150 & 130 \\
Corporações & 20 & 100 & 100 & 100 & 150 & 100 \\
\hline
\end{tabular}

Fonte: Basle Committee on Banking Supervision (1999: 31)

Notas: (1) Ponderação de risco baseada na ponderação de risco-país no qual o banco está sediado. (2) Ponderação de risco baseada na avaliação de um banco individualmente. (3) Ativos de curto prazo de maturação, por exemplo, menos de 6 meses, poderão receber uma ponderação de risco de uma categoria mais favorável que a ponderação usual desses ativos.

As novas regras também procuram reduzir, apesar de não eliminarem, o viés a favor dos empréstimos interbancários de curto prazo do Acordo de Basiléia de 1988. Nesse acordo, os empréstimos de curto prazo intrafronteiras são considerados de baixo risco, estimulando os bancos a concederem empréstimos interbancários. $\mathrm{Na}$ nova proposta sobre a estrutura de adequação de capital dos bancos, tanto os empréstimos para bancos de ratings reduzidos (segundo as principais agências) quanto para bancos sediados em países que tenham ratings baixos terão uma ponderação de risco menos favorável relativamente aos bancos com qualidade de crédito mais elevada. Contudo, o Comitê da Basiléia continua propondo que os em-

\footnotetext{
${ }^{7}$ O IIF foi criado em 1983 após a declaração da moratória mexicana por 38 bancos internacionais. Atualmente, possui entre seus membros, além de bancos comerciais e de investimentos, investidores institucionais, corretoras, sediados em mais de 50 países. Após analisar e discutir a nova proposta do Basle Committee, o IIF divulgou um relatório no qual apresenta a concordância com a maior parte das novas proposições do BIS, porém sugere a adoção de diretrizes semelhantes para as instituições financeiras não-bancárias de modo a garantir igualdade de competição (IFF, 2000).
} 
préstimos para bancos com maturidade de 6 meses ou menos recebam uma ponderação de risco mais favorável do que os empréstimos de longo prazo (Goldstein, 1999).

O segundo pilar refere-se aos métodos de supervisão e favorece o estilo de supervisão britânico de revisão contínua. Isso incluiu a flexibilidade de exigir uma reserva de capital além do nível mínimo de $8 \%$, de acordo com o grau de sofisticação das relações e da capacidade do banco de estabelecer um padrão de controle interno. Testes de estresse também são encorajados. ${ }^{8}$

O terceiro pilar é uma tentativa de incluir nessa complexa equação a disciplina de mercado, concedendo aos participantes do mercado, tais como os acionistas, informações suficientes para viabilizar uma avaliação da gestão dos riscos efetuados pelos bancos e seus níveis de adequação de capital. Esse aspecto foi objeto de um documento complementar divulgado em janeiro de 2000, A New Capital Adequacy Framework: Pillar 3 Market Discipline (Basle Committee, 2000), o qual procura aprofundar a discussão de algumas propostas de fortalecimento do papel do mercado no monitoramento da adequação de capital, mediante maior transparência e comparabilidade das informações.

O documento final, que estava previsto para ser divulgado no segundo semestre de 2000, após o término das consultas, deverá ser diferente do divulgado em junho de 1999. Também haverá negociação em paralelo para a nova diretiva européia de adequação de capital. Todavia, a leitura do documento inicial suscita algumas inquietações. Por um lado, as novas regras podem conduzir a uma reorganização dos mercados financeiros domésticos e internacional de modo a beneficiar um número reduzido de bancos líderes, bem como estimular a convergência dos sistemas financeiros domésticos em direção ao modelo anglo-saxão, desconsiderando especificidades institucionais dos diferentes países.

Por exemplo, no que se refere à recomendação de utilização de ratings externos, apenas as corporações americanas são amplamente avaliadas e, mesmo assim, apenas quando emitem títulos de dívida. Na Europa é diferente, embora a cultura do rating esteja começando a se desenvolver. Os supervisores alemães estão preocupados com o fato de que milhares de médias empresas alemãs podem ter seu acesso ao crédito bancário penalizado, já que os bancos terão de efetuar aprovisionamento de $100 \%$ para as empresas que não tenham seu risco classificado por um agência externa de avaliação de risco. Igualmente, a diferença entre "AA-" e "A+" é quase nula em termos de risco de falência, mas implica um salto de 20 a $100 \%$ no aprovisionamento de capital no caso de uma corporação.

\footnotetext{
${ }^{8}$ Um estudo sobre testes de estresse adotados por vinte grandes instituições financeiras internacionais foi realizado pelo Comitê de Finanças Globais do BIS para avaliar a eficácia em termos da prevenção de fatores de risco associados a eventos possíveis, mas excepcionais (Committe on the Global..., 2000). Todavia, as conclusões dessa investigação são ambíguas na medida em que consideram que "sob condições ideais" tais testes podem ser úteis e que portanto devem continuar sendo utilizados como instrumento de administração de risco. Porém, o próprio Comitê reconhece que não há nada que assegure a ocorrência das tais condições ideais.
} 
Por outro lado, no que se refere aos países periféricos, as condições de acesso desses países ao mercado internacional de crédito devem se deteriorar. Para os países membros da OCDE, as novas regras devem ter um efeito imediato sobre os spreads pagos pelos governos e pelas instituições bancárias residentes, já que os ratings externos substituirão o critério ainda vigente, fixado pelo acordo de 1988, de o país ser membro ou não da OCDE. Alguns países em desenvolvimento, classificados medianamente pelas agências de rating, como México, Coréia, Grécia, Turquia e Hungria, pagam atualmente spreads inferiores ao demais "mercados emergentes" exatamente por serem membros dessa organização (grau de ponderação de risco de $0 \%)^{9}$.

Os demais países periféricos também devem ser penalizados por uma elevação e maior volatilidade dos spreads no mercado de crédito bancário. Nos anos 90, os spreads sobre a Libor vigentes nesse mercado foram menos voláteis e inferiores, na média, aos spreads sobre os bônus (112 pontos versus 256 pontos). Essas diferenças decorrem, em grande parte, das especificidades dos dois mercados. No mercado de crédito bancário, a maior parte das operações foram realizadas por sindicatos de bancos que, por serem um grupo coesivo, têm mais condições de fazer valer um contrato e maior facilidade de renegociar dívidas do que os detentores de bônus (grupo numeroso e heterogêneo). Ademais, os bancos estabelecem relações de longo prazo com os devedores e têm acesso a informações privilegiadas, o que ampliaria tanto a capacidade de monitoramento dos projetos quanto a avaliação do risco de crédito dos devedores (Eichengreen e Mody, 1999). Assim, o risco de default embutido no spread acaba sendo menor. ${ }^{10}$

Já no mercado de bônus, os spreads seguiram praticamente parri passu os ratings externos das agências de classificação de risco de crédito, cuja evolução foi extremamente volátil ao longo dos anos $90 . \mathrm{Na}$ realidade, as avaliações dessas agências não foram mais precisas e rigorosas do que as realizadas pelas instituições financeiras. Pelo contrário, essas avaliações foram altamente suscetíveis às mudanças na percepção do mercado em relação à probabilidade de uma empresa ou país deixar de honrar suas obrigações e não responderem, prontamente, aos sinais de deterioração dos fundamentos econômicos dos "mercados emergentes" ao longo dos anos 90 .

Para que a utilização de classificação externa de risco se torne um padrão global serão necessárias agências especializadas em rating em todos os países que avaliem não apenas empresas que emitam títulos de dívida, mas também aquelas que se financiam exclusivamente mediante empréstimos bancários. Empresas que recorrem às agências de rating e forem classificadas abaixo de "B-" são penalizadas com $150 \%$ de aprovisionamento, enquanto as empresas sem avaliação automati-

\footnotetext{
${ }^{9}$ Por exemplo, um banco estrangeiro que conceder crédito para a Grécia (país classificado como BBB) precisará comprometer capital equivalente a $4 \%$ da posição (Shireff, 1999).

${ }^{10}$ Sobre o comportamento dos spreads dos países "emergentes" nos mercados bancários nos anos 90, ver também Kain e Kleist (1999).
} 
camente exigem provisão de $100 \%$. Haverá portanto um incentivo para as empresas que não são excelente risco a não procurar obter uma avaliação. A única agência que divulga ratings não solicitados é a Moody's. Existe ainda a probabilidade de que se generalizem os ratings baseados em informações financeiras divulgadas pelo emissor bem como informações adicionais de domínio público, os chamados PI, como os que a Standard \& Poor's oferece. Esse tipo de rating certamente será usado pelos bancos que vão procurar mitigar a provisão de capital para os seus empréstimos, pelo menos até que eles passem a utilizar seus ratings internos, sujeitos à aprovação das autoridades domésticas de supervisão, objetivo de mais longo prazo do primeiro pilar das novas regras do BIS. Desse modo, com a nova diretriz, "a ponderação dos risco se tornará uma commodity que poderá ser manipulada por bancos, seus clientes e agências locais de rating que irão proliferar” (Shireff, 1999).

\section{O FUTURO DO FMI E DO BIRD}

Várias propostas de reestruturação dessas instituições têm sido elaboradas desde a eclosão da crise asiática, algumas com maior probabilidade de sucesso do que outras, dentre as quais destacam-se as propostas de reforma apresentadas tanto pelo congresso quanto pelo governo dos EUA, país que detém a maioria das cotas, e que, assim, exerce uma influência decisiva nas políticas adotadas pelas instituições de Bretton Woods. Na "Reunião da Primavera" do FMI e BIRD, realizada durante a segunda semana de abril de 2000 em Washington, o centro da discussão foi exatamente a reforma das duas instituições e o novo papel que devem desempenhar nos próximos anos. Contudo, mudanças efetivas devem ocorrer somente na reunião de setembro, tradicionalmente o encontro principal das duas instituições (Malta, 2000).

A proposta do Congresso americano, consolidada no Relatório Meltzer (Meltzer Report), recomenda uma reestruturação radical do FMI e do BIRD. Esse relatório começou a ser elaborado em novembro de 1998 pela International Financial Institution Advisory Commission, instituída oficialmente por uma maioria republicana do Congresso, cujo objetivo era avaliar o papel desses organismos multilaterais, diante das críticas de vários setores da sociedade americana e da oposição dos congressistas republicanos ao desembolso de US\$ 18 bilhões efetuado pelos EUA em 1998 para reforçar o caixa do FMI ${ }^{11}$. Essa Comissão, sob a liderança do pro-

\footnotetext{
$11 \mathrm{O}$ aumento da participação dos Estados Unidos nas cotas do FMI havia sido autorizado pela Lei 3.141 de 27 de janeiro de 1998. Esse Ato previa, contudo, que o Tesouro americano orientasse o representante do país junto ao Fundo para promover mudanças radicais em seu relacionamento com os países em desenvolvimento (US House, 1998). Igualmente, a legislação previa a constituição de uma Comissão que avaliasse o desempenho das denominadas Instituições Financeiras Internacionais nas quais o Estados Unidos detêm participação, incluindo o BIRD, os Bancos Regionais de Desenvolvimento (América Latina, África, Ásia), o BIS e a Organização Mundial de Comércio (WTO) (Meltzer et al., 2000). Uma outra lei de 1999, Foreign Operation, Export Financing and Related Programs
} 
fessor Allan Meltzer, levantou informações, encomendou estudos e tomou depoimentos em audiência pública no Congresso durante seis meses. Finalmente, em março de 2000, divulgou o relatório final de suas atividades (Meltzer et al. 2000). Cabe destacar que, dos 11 membros da Comissão, três votaram contra as conclusões do relatório e registraram em separado suas divergências ${ }^{12}$.

Segundo esse Relatório, o FMI deveria concentrar seus esforços na correção de uma grande falha de mercado, os pânicos financeiros, durante os quais mesmo economias solventes não conseguiriam obter financiamento ${ }^{13}$. O FMI deveria extinguir os acordos de empréstimos com condicionalidades e passar a conceder ajuda somente para os países que cumprissem algumas pré-condições, incluindo sistemas bancários sólidos, liberdade irrestrita de entrada e operação de bancos estrangeiros, políticas fiscal, monetária e cambial prudentes, maior transparência das informações e dados econômicos, o que, por sua vez, constituiria um incentivo à adoção de padrões financeiros e políticas macroeconômicas adequados. $\mathrm{O}$ Fundo deveria retomar sua função original e deixar de estruturar grandes pacotes financeiros. Os empréstimos deveriam ser de curto prazo a taxas de juros punitivas e não seriam mais concedidos recursos a taxas subsidiadas aos países mais pobres. Somente em situações de crise sistêmicas, que ameacem a estabilidade financeira internacional, os países não elegíveis deveriam receber recursos do Fundo. A linha de crédito Enhanced Structured Adjustment Facility, que o FMI propôs, em setembro de 1999, transformar em um programa para redução da pobreza e promoção do crescimento (Poverty Reduction and Growth Facility), deveria ser fechada, pois representa uma duplicação com a função das entidades multilaterais de desenvolvimento (Meltzer et al. 2000: 25).

Em relação ao papel do BIRD, o Relatório afirma que o banco deveria transferir recursos somente para os países mais pobres, com renda per capita inferior a US\$ 2,5 mil (hoje, concentrados na África) e que não têm acesso aos fluxos privados de capital. Os países de renda média, que têm condições de captar recursos no mercado financeiro internacional, passariam a ter acesso limitado aos recursos do banco. Atualmente, são exatamente esses que absorvem a maior parte dos recursos do banco (proporção que atinge $75 \%$ na América Latina e $90 \%$ na Ásia) (Meltzer

\footnotetext{
Appropriation Act, estabeleceu como obrigatório o envio anual pelo Tesouro de um relatório ao Congresso, indicando todas as medidas tomadas pelo governo no sentido de reformular o FMI (U.S. Department, 1999).

${ }^{12}$ Participaram dessa Comissão, além de Meltzer, responsável pela coordenação dos trabalhos, outros acadêmicos (Charles Calomiris, Jeffrey Sachs, Fred Bergsten, Jerome Levinson, Edwin Faulkener), parlamentares (Tom Campell e Esteban Torres) e especialistas em finanças do setor privado (W. Lee Hoskins, Richard Huber e Manuel Johnson). Votaram contra a aprovação do Relatório Final, Fred Bergsten, Jerome Levinson e Esteban Torres. A despeito de ter votado pela aprovação do Relatório, Richard Huber assinou o adendo de divergências junto com os três membros que votaram contra (Meltzer et al., 2000: 60-3).

${ }^{13}$ Um dos membros da Comissão, Lee Hoskins, considera que essas recomendações são soluções do tipo second best. Em sua opinião, seria melhor para os Estados Unidos e para mundo que o FMI fosse simplesmente extinto (Meltzer et al., 2000: 59).
} 
et al. 2000; The Economist, 2000). Igualmente, defende-se a transformação do BIRD (e também os bancos regionais de desenvolvimento) em agência de fomento, restringindo suas atividades ao fornecimento de assistência técnica, ao provimento de bens públicos regionais e globais e à promoção do aumento de fluxos financeiros privados destinados aos países emergentes. Quanto ao braço financeiro do BIRD, a International Finance Corporation (IFC), que concede financiamento exclusivamente às empresas privadas, considera-se que deveria ser incorporada na estrutura da nova agência. Já em relação à seguradora do grupo, Multilateral Investment Guarantee Agency (MIGA), a qual fornece cobertura para risco político em operações efetuadas por instituições financeiras internacionais privadas com empresas dos países periféricos, o Relatório Meltzer defende a extinção sumária, por considerar que suas atividades podem ser executadas pelo mercado (Meltzer $e t$ al. 2000: 49).

De acordo com o Relatório, a redução dos empréstimos das duas instituições para os países em desenvolvimento de renda média significaria uma menor ingerência estrangeira nos assuntos internos e, assim, um aumento da soberania nacional desses países. Em relação aos países pobres altamente endividados (HIPCS), propõe-se o perdão total das dívidas por parte do FMI e do BIRD. Proposição, com a qual concordam os três membros da Comissão que votaram contra o Relatório.

A proposta do governo americano, que tem sido divulgada por Lawrence Summers, secretário do Tesouro dos EUA, é menos radical em relação à redefinição do papel das duas instituições de Bretton Woods do que a posição defendida pelo Relatório Meltzer. Uma das preocupações do secretário refere-se exatamente à redução da capacidade de ingerência dos EUA nas políticas econômicas dos países de renda média, como Brasil, Tailândia e Bulgária, no caso de uma expressiva redução dos financiamentos do BIRD e do FMI para esses países, como propõe o Relatório Meltzer. No caso do FMI, como as exigências para obtenção de recursos do FMI seriam muito rígidas, apenas um seleto grupo de países seria beneficiado (Summer, 2000: 14).

Os pontos em comum existentes entre o Relatório Meltzer e as proposições do governo Clinton no que se refere ao FMI e ao BIRD são os seguintes:

- a necessidade de uma delineação clara das funções dessas instituições e suas prioridades,

— o foco na maior transparência de informações tanto das instituições quanto dos países que recebem ajuda,

— importância de configurar fortes incentivos para que os países reduzam a vulnerabilidade às crises,

- a necessidade de definir um programa de apoio mais efetivo ao desenvolvimento,

— o perdão das dívidas dos países pobres altamente endividados e a criação de um amplo pool para a concessão de assistência aos países mais pobres,

— o reconhecimento de que os recursos oficiais não devem ser destinados aos países que não cumprem as metas nem implementam as reformas previstas nos acordos assumidos (Geithener, 2000). 
A proposta do governo americano apóia-se, igualmente, num relatório elaborado por uma equipe de acadêmicos patrocinada pelo Conselho das Relações Exteriores, denominado "Safeguarding prosperity in a global financial system: the future international financial architecture", Report of an Independent Task Force (Goldstein, 1999). A partir de um diagnóstico semelhante ao das instituições multilaterais sobre as causas das crises financeiras recentes dos mercados emergentes, que destaca o problema do moral hazard criado pelos pacotes de salvamento do FMI e do G-7, o relatório enfatiza que o FMI deve ser reestruturado no sentido de concentrar seus esforços na prevenção de crises sistêmicas. No caso de crises nacionais, que não ameacem a estabilidade do SFI, o fundo deveria retornar aos limites de acesso normais $(100 \%$ da quota no FMI em termos anuais e $300 \%$ em termos cumulativos) e estimular os países membros a recorreram a fontes de liquidez não-oficiais, a utilizarem esquemas de reescalonamento da dívida externa privada em situações de crise e a implementarem esforços de prevenção de crises financeiras, que incluiriam a adoção de fundamentos macroeconômicos sólidos e de padrões financeiros e códigos de "good practices" internacionais, bem como o manejo prudente do endividamento externo. $\mathrm{O}$ custo dos recursos dos fundos seria indiretamente proporcional a esses esforços:

"No âmbito internacional, precisamos que o FMI lide com os rápidos e infreqüentes, porém sérios, episódios de pânico dos investidores. Os mercados são os melhores alocadores de recursos do que qualquer outra coisa, mas não são infalíveis [...] incentivos para a prevenção e resolução de crises precisarão ser ampliados se o FMI reduzir o tamanho dos empréstimos concedidos aos países em crise, também é necessário que os credores do setor privado assumam uma parcela maior de responsabilidade quando o peso da dívida dos países emergentes se torne insustentável. Em outras palavras, o risco moral pode ser controlado mediante a reforma das práticas de crédito adotadas pelo FMI, não sendo necessário o seu fechamento" (Goldstein, 1999: 88-9).

Já o BIRD deveria ser mais seletivo na concessão de seus empréstimos, concentrando seus esforços nos aspectos estruturais e sociais do desenvolvimento. $\mathrm{O}$ banco deveria financiar a constituição "redes sociais" (social safety nets) e direcionar recursos de longo prazo para as nações mais pobres, que não têm acesso a fontes alternativas de financiamento (Goldstein, 1999). Todavia, o governo rejeita totalmente o argumento defendido no Relatório Meltzer de que o BIRD não deve conceder empréstimos aos países de renda média, por considerar que esses países possuem elevados contingentes de habitantes pobres, cujo acesso à saúde básica, educação e infra-estrutura rural jamais será viabilizado por investimentos exclusivamente privados (Summer, 2000: 13).

A proposta de reforma do governo americano quer, sobretudo, resguardar o papel que essas instituições desempenham como representantes dos interesses dos Estados Unidos. O depoimento de Lawrence Summer ao Comitê Bancário da Câ- 
mara dos Deputados logo após a divulgação do Relatório Meltzer é bastante explícito quanto à isso:

"Senhor Presidente, nós ainda não analisamos detidamente o Relatório, mas, francamente, consideramos que há inúmeras recomendações muito drásticas e problemáticas. Todavia, mesmo não tendo examinado completamente as recomendações do Relatório, acreditamos que, se tomadas literalmente, poderemos enfraquecer estas instituições de tal forma que não serão mais aptas para divulgar os valores centrais e os interesses da América no mundo. A combinação de restrições que o Relatório propõe poderá essencialmente comprometer a capacidade destas instituições em auxiliar países tão diversos como o México, Bulgária e Tailândia. Isto poderá colocar em risco salários americanos, poupança americana e a segurança americana" (Summer, 2000: 12)

\section{CONSIDERAÇÕES FINAIS: CONSEQÜÊNCIAS PARA A SOBERANIA NACIONAL DOS PAÍSES PERIFÉRICOS}

Nas seções precedentes, procurou-se resumir as principais iniciativas e recomendações de política do FMI, BIS e do Congresso e do governo americano, voltadas para o "aperfeiçoamento" do sistema financeiro internacional. Uma análise preliminar poderia sugerir a existência de uma contradição entre, de um lado, as novas regras propostas pelo Comitê da Basiléia, que devem tornar as condições de acesso dos países periféricos aos fluxos de crédito privados mais adversas, e, de outro lado, as propostas de reestruturação do FMI e BIRD apresentadas pelo Congresso e governo americanos, que envolveriam, além da redução nos empréstimos oficiais para esses países e da imposição de pré-condições mais rígidas para a sua obtenção, um maior envolvimento do setor privado na prevenção e resolução das crises. Contudo, essa contradição é apenas aparente ${ }^{14}$. $\mathrm{Na}$ realidade, existe uma lógica geral subjacente a todas essas iniciativas. Como mencionado na seção II, o "fortalecimento da arquitetura financeira internacional", cujas linhas gerais foram definidas pelo FMI, significa aperfeiçoar o sistema atual, de modo a garantir a manutenção do ambiente de globalização financeira. Nesse contexto, a prevenção das crises financeiras dos países em desenvolvimento, que se revelaram uma das principais ameaças à "estabilidade" do sistema, requer o aumento da eficácia da "disciplina de mercado" no sentido de evitar a absorção de volumes excessivos de capitais externos por parte desses países.

\footnotetext{
${ }^{14}$ Vale mencionar que o Task Force Report defende explicitamente a vinculação entre os spreads das dívidas dos mercados emergentes e dos riscos de crédito definidos pelas agências privadas de rating, as quais seriam sujeitas a uma menor pressão política. Contudo, recomenda que durante um período de transição os ratings sejam estabelecidos pelo FMI.
} 
A ênfase no aumento da transparência em relação à situação macroeconômica e financeira dos países e a adoção de códigos de "boa prática" decorre da crença de que a redução das assimetrias de informações e das falhas institucionais minimizará o risco de tomada de decisões incorretas pelos agentes, tornando, assim, o mercado mais eficiente num contexto financeiro liberalizado. Ademais, nesse contexto, a "disciplina de mercado" tornar-se-á mais eficaz, na medida em que o setor privado passará a discriminar os países que não aderirem às novas práticas (Blanden, 1999).

Contudo, para que o mercado funcione de forma adequada, não é suficiente a minimização dos problemas de assimetria de informações. Como mencionado na Introdução deste artigo, os últimos relatórios dos organismos multilaterais (bem como o Task Force Report) reconhecem que, mesmo na ausência desse problemas, os mercados podem falhar. Por um lado, os problemas de risco moral (associados a garantias explícitas ou implícitas) também podem eliminar ou reduzir a efetividade da disciplina de mercado, pois induziriam bancos e investidores a subestimarem os riscos envolvidos em suas aplicações nos mercados emergentes. Por outro lado, as instituições financeiras podem ser negligentes na avaliação e no monitoramento do risco de crédito dos devedores.

A resolução do problema de risco moral seria atingida mediante a redefinição da forma de atuação do FMI e do BIRD no sentido de reduzir a disponibilidade de recursos oficiais para os países em desenvolvimento da América Latina e da Ásia. Apesar das diferenças de ênfase, tanto a proposta do congresso americano (Meltzer Report) quanto da Casa Branca (Task Force Report) teriam esse desdobramento. Conseqüentemente, esses países passariam a depender, de forma quase exclusiva, das fontes privadas de financiamento. Para ter acesso aos recursos oficiais, os países teriam que cumprir um conjunto ainda mais amplo de pré-condições. Vale lembrar que mesmo o acesso à Contingent Credit Line está sujeito a várias condicionalidades, que incluem além da perseguição de políticas macroeconômicas consistentes, a adoção dos padrões internacionais de boa conduta e a participação no SDDS. Já o maior envolvimento do setor privado na prevenção e resolução das crises, proposto pelo FMI, também contribuiria para limitar o risco moral.

As novas regras de adequação de capital da Basiléia - que vincula os custos dos empréstimos dos países em desenvolvimento aos rating das agências de classificação de risco de crédito - além de procurarem resolver o problema da inadequação dos sistemas de avaliação e monitoramento de crédito dos bancos, constituem um instrumento fundamental para reforçar a "disciplina de mercado". As agências de ratings tornaram-se agentes fundamentais dos mercados financeiros internacionais no contexto atual de predominância das finanças de mercado. Sua função primordial é exatamente avaliar a capacidade de pagamento dos devedores e tornar pública e homogênea essa informação. Para isso, elas dispõem, em princípio, de informações mais amplas e de uma maior expertise na apreciação dos riscos de crédito, relativamente às instituições financeiras (Orléan, 1999). A redução de uma nota funciona como um sinal de alerta para o conjunto de comunidade finan- 
ceira, provocando uma mudança de comportamento de todos os participantes do mercado.

Assim, se essas iniciativas forem implementadas, somente os países periféricos que cumprirem as "lições de casa" - agora, muito mais amplas, pois envolvem, além das políticas macroeconômicas, a regulamentação e supervisão dos sistemas financeiros, a adoção dos códigos de good practice etc. - terão acesso aos fluxos de capitais, sejam oficiais, sejam privados. Ademais, se as novas regras do BIS forem adotadas, as condições de acesso ao mercado internacional de crédito devem se tornar mais perversas para aqueles países que não conseguirem uma boa avaliação das agências de rating, em termos de aumento do custo e da volatilidade dos fluxos, como mencionado na seção III. Ou seja, o suposto "aperfeiçoamento" do sistema financeiro internacional significará uma intensificação das assimetrias entre países centrais e periféricos e uma redução adicional do raio de manobra na definição das políticas econômicas nacionais.

O aumento do grau de soberania nacional enfatizado pelo Relatório Meltzer é totalmente ilusório. A diferença é que a "disciplina do mercado" seria o principal instrumento de pressão sobre os países, substituindo a fiscalização do FMI e do BIRD.

Ou seja, no novo modelo, a punição ao não cumprimento das "lições de casa" passaria a ser feita, predominantemente, pelo setor privado e, em especial, pelas agências de rating.

É possível indagar por que não adotar uma nova arquitetura internacional que incorpore, como na proposta original de Keynes em Bretton Woods, sanções também para os países centrais que apresentarem contínuos desequilíbrios em seus balanços de pagamento?

\section{REFERÊNCIAS BIBLIOGRÁFICAS}

ADAMS, Charles et al. (1998) International capital markets: Developments, Prospects and Key Policies Issues. Washington, DC: International Monetary Fund, vol. 1.

(1999) International Capital Markets: Developments, Prospects and Key Policies Issues. Washington, DC: International Monetary Fund, vol. 1 e 2.

AKYÜZ, Y. (1998) The East Asian Financial Crisis: Back to the Future. Genebra: UNCTAD (mimeo). Disponível na Internet (http://www.unctad.org/en/pub/prasia98.htm).

BAER, Monica (1995) “Os Desafios à Reorganização de um Padrão Monetário Internacional”. Economia e Sociedade, 4, Campinas: IE-Unicamp: 79-126. Junho.

BASLE Committee on Banking Supervision (1988) International Convergence of Capital Measurement and Capital Standards. Basiléia: Bank for International Settlements, Julho, atualizado para Abril de 1997.

(1997). Core Principles for Effective Banking Supervision. Basiléia: Bank for International Settlements, Abril.

(1999) A New Capital Adequacy Framework. Basiléia: Bank for International Settlements, Junho.

(2000) A New Capital Adequacy Framework: Pillar 3 Market Discipline. Basiléia: Bank for International Settlements, Janeiro.

BLANDEN, Michel (1997) “Can the risks be seen?”. The Banker, Londres: Financial Times Magazines. Maio: 32-7. 
BLANDEN, Michel (1999) “More transparency, please”, The Banker, Maio: 22-5

COMMITTEE ON THE GLOBAL FINANCIAL SYSTEM (2000) Stress Testing by Large Financial Institutions: Current Practice and Aggregation Issues. Basiléia: Bank for International Settlements, Committee on the Global Financial System. Março.

CUNHA, André Moreira e PRATES, Daniela M. (1999). "Instabilidade Financeira nos Anos 90: a Reação Conservadora”. Anais da II Jornada de Economia Política do Capitalismo Contemporâneo - XXVII Encontro Nacional de Economia ANPEC. Belém (PA), 7 a 10 de Dezembro.

(The) ECONOMIST (2000) "Slimming the Bretton Woods Duo", Economic focus, The Economist, 18 de Março: 80.

EICHENGREEN, Barry e MODY, Ashoka (1999) "Lending Booms, Reserves and the Sustainability of Shortterm Debt: Inferences from the Pricing of Syndicated Bank Loans”, NBER Working Paper Series, Working Paper 7113, National Bureau of Economic Research, Cambridge, Maio.

FREITAS, M. Cristina P. e PRATES, Daniela M. (2000) “As Novas Regras da Supervisão Bancária do BIS e Seus Efeitos para os Países Periféricos”. Aceito para publicação na Revista Análise Econômica.

GEITHENER, Timothy F. (2000) "IMF and Other Financial Institutions”, Congressional Testimony before the Senate Committee on Banking. Washington, DC: US Treasury, 27 de Abril. Disponível na Internet http://www.treas.gov.press/releases/ps583.htm.

GOLDSTEIN, Morris (project director) (1999) "Safeguarding Prosperity in a Global Financial System: the Future International Financial Architecture”, Report of An Independent Task Force, sponsored by the council on foreign relations, Institute of International Economics, Washington, DC.

IFF - Institute of International Finance (2000) Leading bankers make major proposal to strengthen the international banking system. Hague: Press Release, 12 de Abril, (http://www.iif.com/PressRel/ BCBS2000.html).

IMF - International Monetary Fund (1998a) World Economic Outlook. Washington DC: International Monetary Fund, Maio.

(1998b) World Economic Outlook. Washington DC: International Monetary Fund, Outubro. (1999a) World Economic Outlook. Washington DC: International Monetary Fund, Maio.

(1999b) World Economic Outlook. Washington DC: International Monetary Fund, Setembro.

KAIN, Steven B e KLEIST, K. von (1999) "The Evolution and Determinants of Emerging Market Credit Spread in the 1990s”. Basiléia: Bank for International Settlements (BIS Working Papers n ${ }^{\circ} 68$ ), Maio.

KEYNES, John. M. (1936) The General Theory of Employment, Interest and Money. Londres: MacMillan, Royal Economic Society, (The Collected Writings of John Maynard Keynes, vol. VII), 1973.

MALTA, Cynthia (2000) “FMI e BIRD Abrem Debate de seu Próprio Futuro”. Gazeta Mercantil, São Paulo, 11 de Abril: B-5.

MELTZER, Allan et al. (2000) Final Report of the International Financial Advisory Commission. Senate Banking Committee, Documents. Março. Disponível na Internet (http://phanton-x.gsia.cmu. edu/ banking/docs/docs.htm).

ORLÉAN, André (1999) Le Pouvoir de la Finance. Paris: Éditions Odile Jacob.

PRATES, Daniela M. (2000) “Abertura Financeira e Vulnerabilidade Externa”. In: Gestão Estatal no Brasil: Armadilhas da Estabilização 1995-1998. São Paulo, Edições Fundap.

SHIREFF, David (1999) “Too Far, Too Fast?” Euromoney. Londres: Euromoney Institutional Investor PLC, Agosto: 22-5.

SMALHOUT, James (1998) "Can the IMF Play the Supercop?”, Euromoney, Londres: Euromoney Institutional Investor PLC, Setembro: 90-3.

SUMMER, Lawrence (2000) "Testimony Before the House Banking Committee”. 23 de Março. Disponível na Internet (http://www.treas.gov/press/releases/ps480.htm). 
TAYLOR, Lance (1998) “Lax Public Sector, Destabilizing Private Sector”, Working Paper Series III, Centre for Economic Analysis, New School for Social Research.

UNCTAD - United Nations Conference on Trade and Development (1998). Trade and Development Report. Genebra: UNCTAD.

US DEPARTMENT of the Treasury (1999). Report on IMF Reforms. Report to Congress. $1^{\circ}$ de Outubro; (Atualizado em Marco de 2000). Disponível na Internet (www.treas.gov/press/releases/docs/ imfrefor.pdf).

US HOUSE of Representatives (1998). International Monetary Fund Reform and Autorization Act. $105^{\text {th }}$ Congress, H. R. 3114, 27 de Janeiro. Disponível na Internet (http://thomas.loc.gov/cgibin/ c105:HT3114.IH).

WORLD BANK (1998). World Development Report, 1998, Washington, DC: World Bank. (1999). World Development Report, 1999/2000, Washington DC: World Bank. 